\title{
Thermolabile methylenetetrahydrofolate reductase gene and the risk of cognitive impairment in those over 85
}

\author{
J Gussekloo, B T Heijmans, P E Slagboom, A M Lagaay, D L Knook, R G J Westendorp
}

Section of Gerontology and Geriatrics, Department of General Internal Medicine, Leiden University Medical Center, Leiden, The Netherlands

J Gussekloo

A M Lagaay

D L Knook

R G J Westendorp

Gaubius Laboratory, TNO Prevention and Health, Leiden, The

Netherlands B T Heijmans

P E Slagboom

D L Knook

Department of Clinical Epidemiology, Leiden University Medical

Center, Leiden, The

Netherlands

R G J Westendorp

Correspondence to: Dr Jacobijn Gussekloo, Section of Gerontology and Geriatrics, Department of General Internal Medicine, Leiden University Medical Centre, PO box 9600,2300 RC Leiden, the Netherlands. Telephone 0031715266640 ; fax 003171 5248159; email Leiden85plus@aig.ozl.nl

Received 5 February 1999 and in revised form 5 May 1999 Accepted 13 May 1999

\begin{abstract}
Objectives-Previous reports have shown raised plasma concentrations of homocysteine in older persons with cognitive impairment. This may be caused by environmental and genetic factors. The relation between cognitive function and a common alalval mutation in the methylenetetrahydrofolate reductase (MTHFR) gene was studied in those over 85. Homozygous carriers of this mutation are characterised by a lifelong exposure to moderately raised plasma concentrations of homocysteine.

Methods-In the Leiden 85-plus Study, a population based study of persons aged 85 years and over, the score on the mini mental state examination (MMSE) and the presence of dementia dependent on the MTHFR genotypes were compared in 641 participants (456 women, 185 men) at baseline. In addition, the association between the MTHFR genotype and cognitive decline was studied by re-examining cognitive function of 172 participants without dementia at baseline after a median follow up of 4.0 years.
\end{abstract}

Results-At baseline, carriers of the alal ala genotype had a median MMSE score of 27 points (interquartile range (IQR) 21.5-29), for the alalval genotype it was 26 points (IQR 20-29), and for the vallval genotype it was 27 points (IQR 20-28.3) $(p=0.3)$. The prevalence of dementia was also not significantly different for the various genotypes (alalala $22 \%$, alalval $28 \%$, vallval $27 \%$; $\mathrm{p}=0.4$ ). None of the carriers of the vallval genotype without cognitive impairment at baseline developed dementia during the follow up.

Conclusions-Although previous studies have shown that older persons with cognitive impairment have raised plasma concentrations of homocysteine, homozygosity for the ala to val mutation in the MTHFR gene is not a genetic risk factor for cognitive impairment in persons aged 85 years and over.

(F Neurol Neurosurg Psychiatry 1999;67:535-538)

Keywords: methylenetetrahydrofolate reductase gene; cognitive impairment
High circulating concentrations of homocysteine in carriers of a genetic deficiency of cystathionine $\beta$-synthase-that is, homocysteinuria-cause premature atherosclerosis and cognitive impairment at middle age. ${ }^{1}$ It has yet to be determined whether moderately increased concentrations of homocysteine give rise to cognitive impairment at an older age. Several studies have reported on increased plasma concentrations of homocysteine in older persons with cognitive impairment. ${ }^{2-6}$ The associations from these cross sectional surveys, however, do not necessarily imply causality, because plasma concentrations of homocysteine are influenced by various environmental factors such as folate status, malnutrition, renal failure, hypertension, recent cardiovascular events, cigarette and coffee consumption, and lack of exercise. ${ }^{17}$

Recently, a common $\mathrm{C}_{677}$ to $\mathrm{T}$ (ala to val) mutation in the methylenetetrahydrofolate reductase (MTHFR) gene was identified that leads to a moderate disturbance of the methionine/homocysteine metabolism by rendering the enzyme thermolabile. ${ }^{8}$ On average the carriers of the homozygous mutated genotype val/val, $9 \%$ to $13 \%$ of the white population, have increased plasma concentrations of homocysteine compared with heterozygous and non-carriers. ${ }^{9-11}$ In healthy young males the plasma concentrations vary from $10.0 \mu \mathrm{mol} / 1$ in carriers of the normal genotype, $10.4 \mu \mathrm{mol} / 1 \mathrm{in}$ heterozygous, and $16 \mu \mathrm{mol} / 1$ in homozygous carriers of the mutated genotype. ${ }^{11}$

We tested the hypothesis that homozygous carriers of the MTHFR polymorphism, reflecting a long term moderately increased plasma concentration of homocysteine, are at risk of cognitive impairment at an older age. As part of the Leiden 85-plus Study, we genotyped 641 participants for the MTHFR polymorphism who were repeatedly evaluated for cognitive function and the presence of dementia.

\section{Materials and methods}

The Leiden 85-plus Study is a population based, prospective follow up study of morbidity and mortality in the oldest old. The design of the study is reported elsewhere. ${ }^{12}$ Briefly, during 1986 to 1988 a total number of 976 inhabitants of the city of Leiden, The Nether- 
Table 1 Cognitive status at baseline stratified for the MTHFR genotypes and sex

\begin{tabular}{|c|c|c|c|c|c|c|}
\hline \multirow[b]{2}{*}{ MTHFR genotype } & \multicolumn{3}{|c|}{ Women $(n=456)$} & \multicolumn{3}{|c|}{$\operatorname{Men}(n=185)$} \\
\hline & ala/ala & ala/val & val/val & ala/ala & ala/val & val/val \\
\hline Number & 213 & 196 & 47 & 84 & 90 & 11 \\
\hline Median age $(y)$ & 89.3 & 89.1 & 89.4 & 89.1 & 89.6 & 88.6 \\
\hline IQR & $87.6-91.4$ & $87.4-91.6$ & $87.9-91.6$ & 87.4-91.4 & $87.7-92.6$ & $87.9-93.8$ \\
\hline Median MMSE (points) & 26 & 25 & 27 & 27 & 27 & 22 \\
\hline IQR & $21-29$ & $20-28$ & $24-29$ & $24-29$ & $21-29$ & $19-27$ \\
\hline Diagnosis of dementia (yes/no) $\dagger$ & $52 / 147$ & $55 / 128$ & $12 / 34$ & $9 / 67$ & $17 / 62$ & $3 / 6$ \\
\hline
\end{tabular}

${ }^{\star} \mathrm{IQR}=$ interquartile range, representing the $25 \%$ and $75 \%$ percentiles of the distribution.

†Total number of participants to the psychiatric interview was 428 women and 164 men.

lands, aged 85 years and over were visited at home by medical doctors. The medical ethics committee of the Leiden University approved the study, and informed consent was obtained from all participants. The baseline visit incorporated the mini mental state examination (MMSE), and a routine blood analysis. After HLA typing, which was a primary goal of the study, sufficient cellular material was available for determination of MTHFR genotypes for 641 of these 891 participants $(72 \%)$. Participants with an MMSE score below 24 points $(n=226)$ were evaluated by a psychiatrist, using the Dutch version of the geriatric mental state schedule to diagnose dementia according to DSM-III criteria. ${ }^{13}$ At baseline 148 participants had dementia whereas 444 participants did not have symptoms of dementia. For 49 participants the diagnosis of dementia was unknown as they refused a psychiatric interview.

Up to 1 March 1992, 233 of the 444 participants without dementia at baseline survived, and 172 participants could be revisited to assess a second MMSE score. Participants with a follow up MMSE score below 24 points $(n=69)$ were evaluated by a medical doctor using the Dutch version of the geriatric mental state schedule-abbreviated. Using the computerised diagnostic system AGECAT, 37 participants had dementia whereas 122 participants did not have symptoms of dementia. Thirteen participants refused a psychiatric interview. ${ }^{14}$

Genomic DNA was extracted from the original samples that dated from 1986-8. MTHFR genotyping was assessed by polymerase chain reaction (PCR) amplification of a $198 \mathrm{bp}$ fragment containing the $\mathrm{C}_{677}$ to $\mathrm{T}$ transition, followed by digestion with HinfI as previously described by Frosst et al. ${ }^{8}$

All continuous data are presented as medians and interquartile ranges (IQRs), representing the $25 \%$ and $75 \%$ percentiles of the distribution. Differences between groups were compared using $\chi^{2}$, Wilcoxon, and KruskalWallis tests, which do not assume an underlying distribution of the data.

\section{Results}

BASELINE MEASUREMENTS

The median age of the 641 participants was 89.1 years (IQR 87.5-91.6). The overall distribution of the MTHFR genotypes was $46 \%$ ala/ ala $(\mathrm{n}=297), 45 \%$ ala $/ \mathrm{val}(\mathrm{n}=286), 9 \%$ val $/ \mathrm{val}$ $(\mathrm{n}=58)$, and was in Hardy-Weinberg equilibrium. The MTHFR distribution was not different between women and men (table $1, \chi_{2}^{2}$ $=3.8, \mathrm{p}=0.2$ ).

The percentage of participants diagnosed with dementia was significantly higher in women than in men $\left(28 \% v 18 \% ; \chi_{1}^{2}=6.5\right.$, $\mathrm{p}=0.01)$. The distribution of the MTHFR genotypes in the 49 persons who refused a psychiatric interview was not different from the distribution in the 592 persons who participated in the interview $\left(\chi_{2}^{2}=0.8, p=0.7\right)$.

The MMSE scores and the prevalence of dementia stratified for the MTHFR genotypes and sex are presented in table 2 . On entry to the study, cognitive function was not dependent on the MTHFR genotype. Among women, the MMSE scores and the prevalence of dementia were virtually similar in carriers of the various genotypes. In men, the MMSE scores were lower and the prevalence of dementia higher in carriers of the val/val genotype, but this did not reach significance (Kruskal-Wallis test $\mathrm{p}=0.2$, and $\chi_{2}^{2}=4.1$, $\mathrm{p}=0.1)$.

FOLLOW UP MEASUREMENTS

In 1992,172 participants (121 women and 51 men) without dementia at baseline were revisited. Their median MMSE score at baseline was 29 points (IQR 27-29). After a median follow up of 4.0 years the median decline in MMSE score was 4 points (IQR 1-7), and was not different for the three genotypes (Kruskall-

Table 2 Changes in cognitive status in participants without dementia at baseline after a median follow up of 4 years, stratified for the MTHFR genotypes and sex

\begin{tabular}{|c|c|c|c|c|c|c|}
\hline \multirow[b]{2}{*}{ MTHFR genotype } & \multicolumn{3}{|c|}{ Women $(n=121)$} & \multicolumn{3}{|c|}{$\operatorname{Men}(n=51)$} \\
\hline & alalala & ala/val & val/val & alalala & ala/val & val/val \\
\hline Number & 59 & 51 & 11 & 28 & 21 & 2 \\
\hline Median MMSE follow up & 24 & 25 & 27 & 26 & 26 & 23.5 \\
\hline IQR & $19-27$ & $19-28$ & $25-29$ & $19.5-28$ & $24-27.5$ & - \\
\hline Median decline of MMSE & 4 & 4 & 2 & 2 & 3 & 4.5 \\
\hline IQR & $2-8$ & $1-9$ & $0-4$ & $1-5.8$ & $2-4.5$ & - \\
\hline Diagnosis of dementia (yes/no) $\dagger$ & $18 / 36$ & $13 / 35$ & $0 / 11$ & $5 / 20$ & $1 / 18$ & $0 / 2$ \\
\hline
\end{tabular}

$\star \mathrm{IQR}=$ interquartile ranges, representing the $25 \%$ and $75 \%$ percentiles of the distribution

†Total number of participants to the psychiatric interview was 113 women and 46 men. 
Wallis test, $\mathrm{p}=0.8$ ). Data were similar when women and men were analysed separately (table 2). During follow up, more women (31 out of $113,28 \%$ ) than men (six out of $46,13 \%$ ) developed dementia $\left(\chi_{1}^{2}=3.8, p=0.05\right)$, but none of those 37 participants was a carrier of the val/val genotype (table 2 ).

The distribution of the MTHFR genotypes in the participants who died during the follow up $(n=211)$ was not different from the distribution in the 172 participants who completed the cognitive measurements $\left(\chi_{2}^{2}\right.$ $=0.07, p=1.0)$. There was also no difference between the genotypic distribution in persons for whom the diagnosis of dementia was unknown $(n=13)$ and the 159 participants who completed the psychiatric interview $\left(\chi_{2}^{2}=1.4\right.$, $\mathrm{p}=0.5)$.

\section{Discussion}

By contrast with general expectation, we found no relation between the common mutation in the MTHFR gene and cognitive impairment in older persons, neither in the cross sectional analysis nor during the follow up. These results did not differ between women and men. Therefore, the data show that homozygosity for the ala/val mutation in the MTHFR gene is not a genetic risk factor for cognitive impairment in the oldest old. These data are in accordance with two recently published case-control studies that found a similar distribution of MTHFR genotypes in persons with and without dementia. ${ }^{15} 16$ However, these findings are at odds with various cross sectional studies that report on an association between the plasma concentration of homocysteine and cognitive impairment..$^{2-6}$

What has to be concluded when increased plasma concentrations of homocysteine are associated with cognitive impairment in older persons, whereas there is no association with the common MTHFR mutation? A possible explanation is that the increased plasma concentration of homocysteine is a phenomenon associated with cognitive impairment or its treatment, instead of being part of the causal mechanism. Particularly in cross sectional studies the possibility that the increased plasma concentrations of homocysteine in persons with cognitive impairment result from secondary environmental changes cannot be excluded. ${ }^{17}$ When studying the distribution of the MTHFR genotypes in relation to cognitive impairment at older age, such a mechanism is not operating as the genetic code is invariable since conception.

A once measured plasma concentration of homocysteine is an inadequate indicator of long term exposure when the impact of moderately increased concentrations of homocysteine is studied as a risk factor of cognitive impairment at older age. Instead, homozygous carriers of the common MTHFR mutation have a lifelong exposure to increased concentrations of homocysteine, but we found the distribution of the genotypes to be similar..$^{9-11}$ Another possibility could be that the number of persons was to small to find significant differences between the MTHFR genotypes and the cognitive measurements. However, the present study is reasonably sensitive in detecting differences in genotypic distributions. It had an $80 \%$ power to detect a significant difference in homozygosity of $8 \%$ between persons with and without dementia, whereas a difference of $2 \%$ was found.

Conflicting results between the outcomes of studies that used plasma concentrations of homocysteine and studies that used the MTHFR polymorphism have been reported for other diseases also. Increased plasma concentrations of homocysteine were associated with the occurrence of stroke in a meta-analysis of cross sectional studies. ${ }^{17}$ However, no association was found between the various MTHFR genotypes and the risk of stroke. ${ }^{18} 19$ Also, within the Leiden 85-plus Study we found no relation between the MTHFR genotype and fatal strokes during a 10 year follow up period. ${ }^{20}$ Similar discrepancies were found for the occurrence of coronary artery disease $\mathrm{e}^{21-23}$ and venous thrombosis. ${ }^{24}$

Alternative hypotheses have been postulated to explain the discrepancies between studies that used plasma concentrations of homocysteine and studies that used the common mutation in the MTHFR gene. Firstly, the increase in plasma homocysteine evoked by the mutation in the MTHFR gene may be insufficient to cause disease in old age, and only in combination with a low folate status will lead to a sufficiently increased plasma concentration and disease. ${ }^{9}$ This explanation is less likely to be relevant for an older population as nutritional deficiencies are relatively common. Secondly, it has been suggested that the mutation causes a redistribution of folate derivatives that have a concomitant beneficial effect. ${ }^{25}$ In this regard it is important to note that within the Leiden 85-plus Study male carriers of the MTHFR mutation are at a significantly higher mortality risk..$^{20}$ This indicates that even within the oldest old the MTHFR mutation is a relevant biological risk factor.

In conclusion, we did not find a relation between the common mutation in the MTHFR gene and cognitive impairment in the oldest old. As carriers of the mutation have had a long term exposure to moderately increased plasma concentrations of homocysteine, the present data do not provide evidence that homocysteine is a risk factor for cognitive impairment in the oldest old.

We thank Simone Droog (TNO Prevention and Health, Leiden) for her technical assistance. This study was funded by grant AG06354 from the US National Institutes of Health, grant 94.047 from the Netherlands Heart Foundation, and a grant from Hersenstichting Nederland (1991).

1 Welch GN, Loscalzo J. Homocysteine and atherothrombosis. N Engl f Med 1998;9:1042-50.

2 Riggs KM, Spiro III A, Tucker K, et al. Relations of vitamin B-12, vitamin B-6, folate, and homocysteine to cognitive performance in the normative aging study. Am F Clin Nutr 1996;63:306-14.

3 Bell IR, Edman JS, Selhub J, et al. Plasma homocysteine in vascular disease and in nonvascular dementia of depressed elderly people. Acta Psychiatr Scand 1992;86:386-90.

4 Jensen E, Dehlin O, Erfurth EM, et al. Plasma homocysteine in 80-years olds: relationships to medical, psychological and social variables. Arch Gerontol Geriatr 1998;26:215-26. 
5 McCaddon A, Davies G, Hudson P, et al. Total serum homocysteine in senile dementia of Alzheimer type. Inter 23 .

6 Joosten E, Lesaffre E, Riezler R, et al. Is metabolic evidence for vitamin B-12 and folate deficiency more frequent in elderly patients with Alzheimer's disease? F Gerontol A Biol Sci Med Sci 1997;52:M76-9.

7 Refsum H, Ueland OM, Nygard O, et al. Homocysteine and cardiovascular disease. Annu Rev Med 1998;49:31-62.

8 Frosst P, Blom HJ, Milos R, et al. A candidate genetic risk factor for vascular disease: a common mutation in methylenetetrahydrofolate reductase. Nat Genet 1995;10:111-3.

9 Jacques PF, Bostom AG, Williams RR, et al. Relation between folate status, a common mutation in methylenetetrahydrofolate reductase and plasma homocysteine concentrations. Circulation 1996;93:7-9.

10 Deloughery TG, Evans A, Sadeghi A, et al. Common mutation in methylenetetra-hydrofolate reductase. Correlation with homocysteine metabolism and late onset vascular diswith homocysteine metabolism and

11 Gudnason V, Stansbie D, Scott J, et al. C677T (thermolabile alanine/valine) polymorphism in methylenetetrahydrofolate reductase (MTHFR): its frequency and impact on plasma homocysteine concentration in different European populations. Atherosclerosis 1998;136:347-54.

12 Weverling-Rijnsburger AW, Blauw GJ, Lagaay AM, et al. Total cholesterol and risk of mortality in the oldest old. Lancet 1997;350:1119-23.

13 Heeren TJ, Lagaay AM, Hijmans W, et al. Prevalence of dementia in the oldest old of a Dutch community. $7 \mathrm{Am}$ Geriatr Soc 1991;39:755-9.

14 Gussekloo J, Heeren TJ, Izaks GJ, et al. A community based study of the incidence of dementia in persons aged 85 years and over. $\mathcal{F}$ Neurol Neurosurg Psychiatry 1995;59:507-10.

15 Tysoe C, Galinsky D, Robinson D, et al. Analysis of $\alpha-1$ antichymotrypsin, presenilin-1, angiotensin-converting enantichymotrypsin, presenilin-1, angiotensin-converting enzyme, and methylenetetrahydrofolate reductase loci as ca
didates for dementia. Am f Med Genet 1997;74:207-12.
16 Chapman J, Wang N, Treves TA, et al. ACE, MTHFR, factor $\mathrm{V}$ Leiden, and apoE polymorphisms in patients with vascu-
lar and Alzheimer's dementia. Stroke 1998;29:1401-4.

17 Selhub J, Dángelo A. Relationship between homocysteine and thrombotic disease. Am F Med Sci 1998;316:129-41.

18 Kostulas K, Crisby M, Huang WX, et al. A methylenetetrahydrofolate reductase gene polymorphism in ischemic stroke and in carotid artery stenosis. Eur f Clin Invest 1998; 28:285-9.

9 Markus HS, Ali N, Swaminathan R, et al. A common polymorphism in the methylenetetrahydrofolate reductase gene, homocysteine and ischemic cerebrovascular disease. Stroke 1997;28:1739-43.

20 Heijmans BT, Gussekloo J, Kluft C, et al. The risk of mortality in men is associated with a common mutation in methylenetetrahydrofolate reductase gene (MTHFR). f Hum Genet 1999 1999;7:197-204.

21 Bockxmeer FM van, Mamotte CDS, Vasikaran SD, et al. Methylenetetra-hydrofolate reductase gene and coronary Methylenetetra-hydrofolate reductase gen

22 Verhoef P, Kok FJ, Kluiitmans LAJ, et al. The 677C-T mutation in the methylenetetra-hydrofolate reductase gene: associations with plasma total homocysteine levels and risk of coronary atherosclerotic disease. Atherosclerosis 1997; 132:105-1

23 Schwartz SM, Siscovick DS, Laminov MR, et al. Myocardial infarction in young women in relation to plasma homocyst(e)ine, folate and a common variant in the methylenetetra-hydrofolate reductase gene. Circulation 1997;96:412-17.

24 Kluijtmans LAJ, den Heijer M, Reitsma PH, et al. Thermolabile methylenetetrahydrofolate reductase and factor $\mathrm{V}$ Leiden in the risk of deep-vein thrombosis. Thromb Haemost 1998;79:254-8.

25 Van der Put NMJ, Van der Heuvel LPWJ, SteegersTheunissen RPM, et al. Decreased methylenetetrahydrofolanissen RPM, et al. Decreased methylenetetrahydro作 $691-4$. 